\title{
USAGE OF PROJECT MANAGEMENT METHODOLOGIES IN FOUNDRIES
}

\author{
1,2Pavel KOLOŠ, ${ }^{3}$ Štefan KOLUMBER, ${ }^{4}$ Jakub ZÁVORKA, ${ }^{5}$ Adam PAWLICZEK \\ ${ }^{1,4}$ VSB - Technical University of Ostrava, Faculty of Materials Science and Technology, Ostrava, Czech Republic, EU, \\ 'pavel.kolos.st@vsb.cz, ${ }^{4}$ jakub.zavorka.st@vsb.cz \\ 2,3Moravian Business College Olomouc, Olomouc, Czech Republic, EU, \\ 22pavel.kolos@mvso.cz, ${ }^{3}$ stefan.kolumber@mvso.cz
}

${ }^{5}$ Moravian Business College Olomouc \& Prague University of Economics and Business, Czech Republic, EU, adam.pawliczek@mvso.cz

https://doi.org/10.37904/metal.2021.4272

\begin{abstract}
The aim of the paper is to analyze and describe current usage of project management methodologies in foundries in Europe, Middle East and Africa (EMEA) region that produce castings for automotive, aerospace and oil \& gas industry. The research goal is to present which project management methodologies are currently the most used and together with that which project managers certification in the research sample. The goal of the paper is also to evaluate the differences between medium size and large size foundries that are also presented in results and discussion of the paper.
\end{abstract}

Keywords: Project, foundry, methodology, casting

\section{INTRODUCTION TO THE RESEARCH}

Effective project management methodology is important and one of the key company areas to cover competitiveness and to ensure final customer satisfaction together with profit maximization. [1]

\subsection{Theoretical Background - Project Management Methodologies}

Project management has a main goal - to set the tools and guidelines to deliver projects outputs within the key parameters - on planned time, in calculated costs and in required quality of product or service. These days, we can find many standards, norms, recommendations how to manage projects. [2] However, there are following most useful standards that are respected worldwide:

1) Project Management Body of Knowledge (PMBOK) - This standard is owned and managed by Project Management Institute (PMI) in USA. This standard has more than 265000 members in more than 170 countries. PMBOK has been established in seventies. Basic idea of PMBOK is process attitude of project management. PMBOK defines five main process groups, nine areas of knowledge, forty-two processes and their connection. Every single process has defined inputs and outputs and tools. The key aspects of PMBOK are framework, activity-focused, customer requirements driven. PMBOK also offers project managers certification. [3]

2) Projects in Controlled Environments (PRINCE2) - Owner of this standard is Office of Government Commerce (OGC) in United Kingdom. PRINCE2 is focused on seven principles, seven processes and seven topics. It is important to understand the principles as for every project an attitude is little bit modified, but the centerline remains. The key aspects of PRINCE2 are methodology, deliverablefocused and business case driven. PRINCE2 offers project managers certification. [4]

3) IPMA Competence Baseline (ICB) - International Project Management Association owns the standard. Comparing to PMBOK and PRINCE2 that are focused on processes, IPMA is focused on abilities and 
competencies of project, program and portfolio managers and their teams. The philosophy of IPMA has three key areas - technical competencies (methods, techniques and tools), behavioral competencies (soft skills) and context competencies (system and integration knowledge and skills). These key areas then defined basic elements and connection for every part of project team. Also, IPMA offers project managers certification. [5]

4) ISO 10006 - Comparing to PMBOK, PRINCE2 and IPMA, ISO 10006 is not a complex project management standard but standard of quality in project management. ISO 10006 is guideline how to describe management of projects in company environment. If a company is ISO 9000 certified and works on project too, project management should be described in accordance with ISO 10 006. [6]

\section{LITERATURE REVIEW}

The most important point of project management methodology choice is to identify which one covers all of the requirements from the strategic, business and project perspective. [7]

It is impossible to say that PRINCE2, PMBOK or IPMA is the best way how to manage the projects in general. The purpose of project management methodology is to propose and define unique set of tools and activities needed to produce required project product in scheduled time plan, planned costs and in required quality. The most useful methodologies in the world are PRINCE2 and PMBOK followed by IPMA. PRINCE2 has its popularity and usage especially in the European companies and PMBOK is very useful in United States. [8]

The process of PMBOK guide project managers in planning, execution, observing and control, close, concept, feasibility, plan and progress, application and realization, production stage and finishing process phases. PRINCE2 process define how to start up, introduce, control, manage boundaries and product delivery and how to close a project. The biggest difference of these methodologies is in the attitude. PMBOK is driven by customer requirements and PRINCE2 is driven by business case. [9]

Current literature offers many researches focused on project management methodologies. Authors of [10] research presented that PRINCE2 methodology, using the planning suspects of work breakdown structure, activity networking and scheduling is very similar with PMBOK which is the key for project managers. Another research [11] presents that it is hard to say which methodology is the most suitable because it depends on the company culture, goals and environment. Research outputs [12] presents the importance of IPMA methodology especially in companies where the project managers have a key role. Authors of research [13] tried to analyze and evaluate all aspects, benefits, advantages and disadvantages of project management methodologies but as the result of the paper, they describe that it is individual to define which methodology is suitable for each enterprise and it is connected with many factors.

Based on these facts, we can see that there are advantages and disadvantages for every project management methodology.

\section{METHODOLOGY OF THE RESEARCH}

Goal of the paper has been set to analyze and describe current usage of project management methodologies in foundries in Europe, Middle East and Africa (EMEA) region based on 2020 data. Academics defined following project management methodologies options in questionnaire to be evaluated - PMBOK, PRINCE2, IPMA, ISO 10 006, OTHER, N/A (not applied). Three research questions were formulated:

1) Which project management methodologies are currently used in EMEA foundries?

2) How many project managers of EMEA foundries have project management certification?

3) What are differences in project management methodologies and project managers certification in medium size and large size foundries? 


\subsection{Collection of research data}

The data were collected in 2020 based on questionnaire that was send into 51 foundries in EMEA region. Totally 38 replies have been collected so the success of return was $74,5 \%$. The structure of our research sample was following:

- 25 medium size companies - foundries (51-250 employees),

- 13 large size companies - foundries (251< employees).

All foundries included in our research produce metal castings for:

- $\quad$ automotive, aerospace, oil \& gas industry.

\section{RESULTS OF THE RESEARCH}

Chapter presents findings of project management methodologies usage research in foundries in EMEA region. Figure 1 presents the data which project methodologies are currently used the most in foundries.

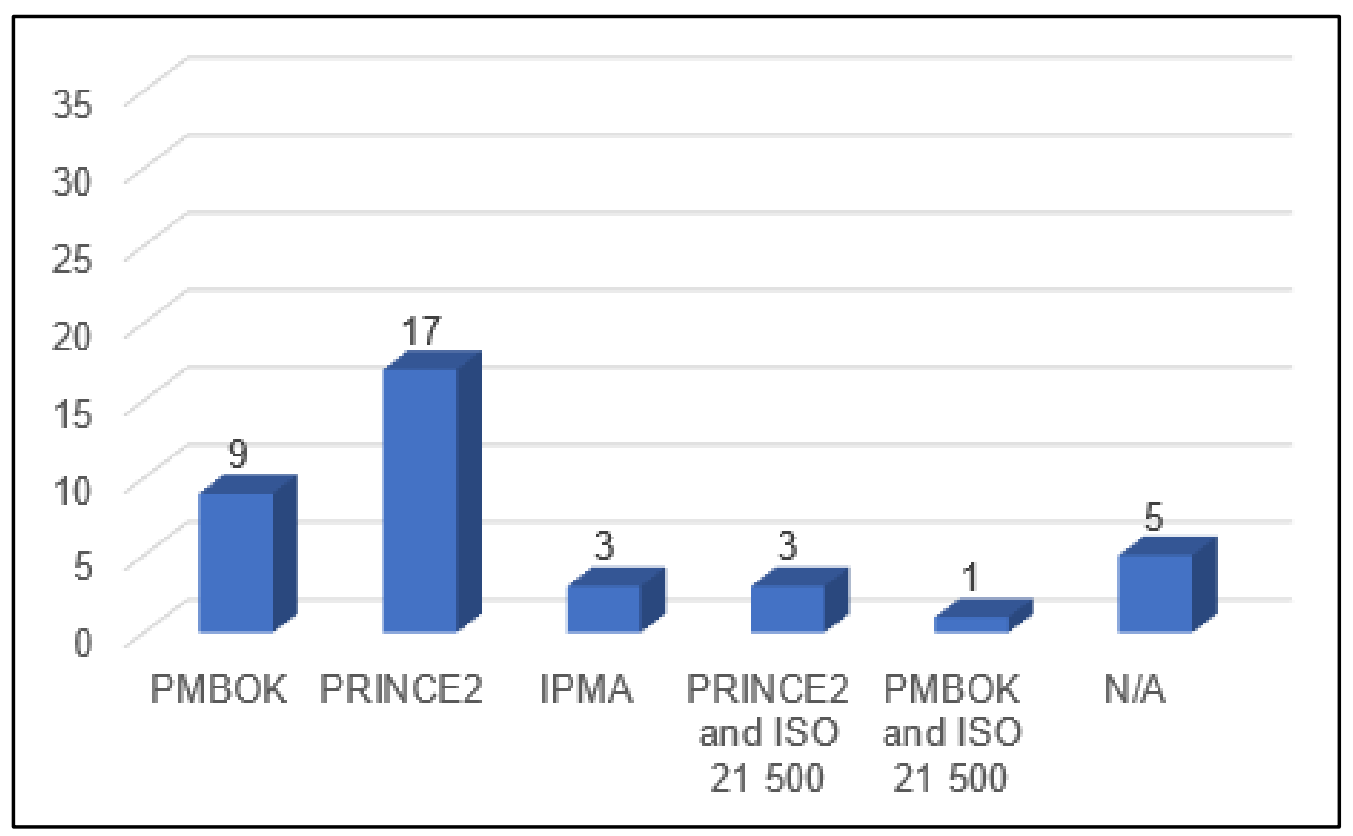

Figure 1 Usage of project management methodologies in EMA foundries

Based on the Figure 1, we can see that the biggest portion has PRINCE2 - 17 foundries (44.7\%). PMBOK is used by 9 foundries (23.6\%). IPMA is implemented only in 3 companies $(7.9 \%)$. The same result as IPMA, has a combination of PRINCE2 and ISO $10006-3(7.9 \%)$. Combination of PMBOK and ISO 10006 is used in 1 foundry (2.6\%). Based on the data in Figure 1, we can say that ISO 10006 is not used separately. There are also 5 representatives $(13.1 \%)$ of N/A which means that 5 companies don't use any project management methodology.

Figure 2 shows the comparison of project management methodologies usage between medium size and large size companies. The results presented in Figure 2 shows that for medium size foundries of our research, the most useful project management methodology is PRINCE2 - 13 companies. The second position is for PMBOK - 7 companies. Interesting finding is that all 5 foundries that do not use any of project management methodologies are from medium size companies. IPMA and combination of IS0 10006 with PRINCE2 or $\mathrm{PMBOK}$ is not used in research sample of medium size foundries. Related to the large size foundries, we can see every foundry of our research uses one of project management methodologies. The most useful 
methodology is PRINCE2 - 4 companies and PRINCE2 together with ISO $10006-3$ companies. The same result as mix of PRINCE2 and ISO 10006 has IPMA - also 3 companies. The rest of the sample is connected with PMBOK. PMBOK only -2 representatives and PMBOK with ISO $10006-1$ representative.

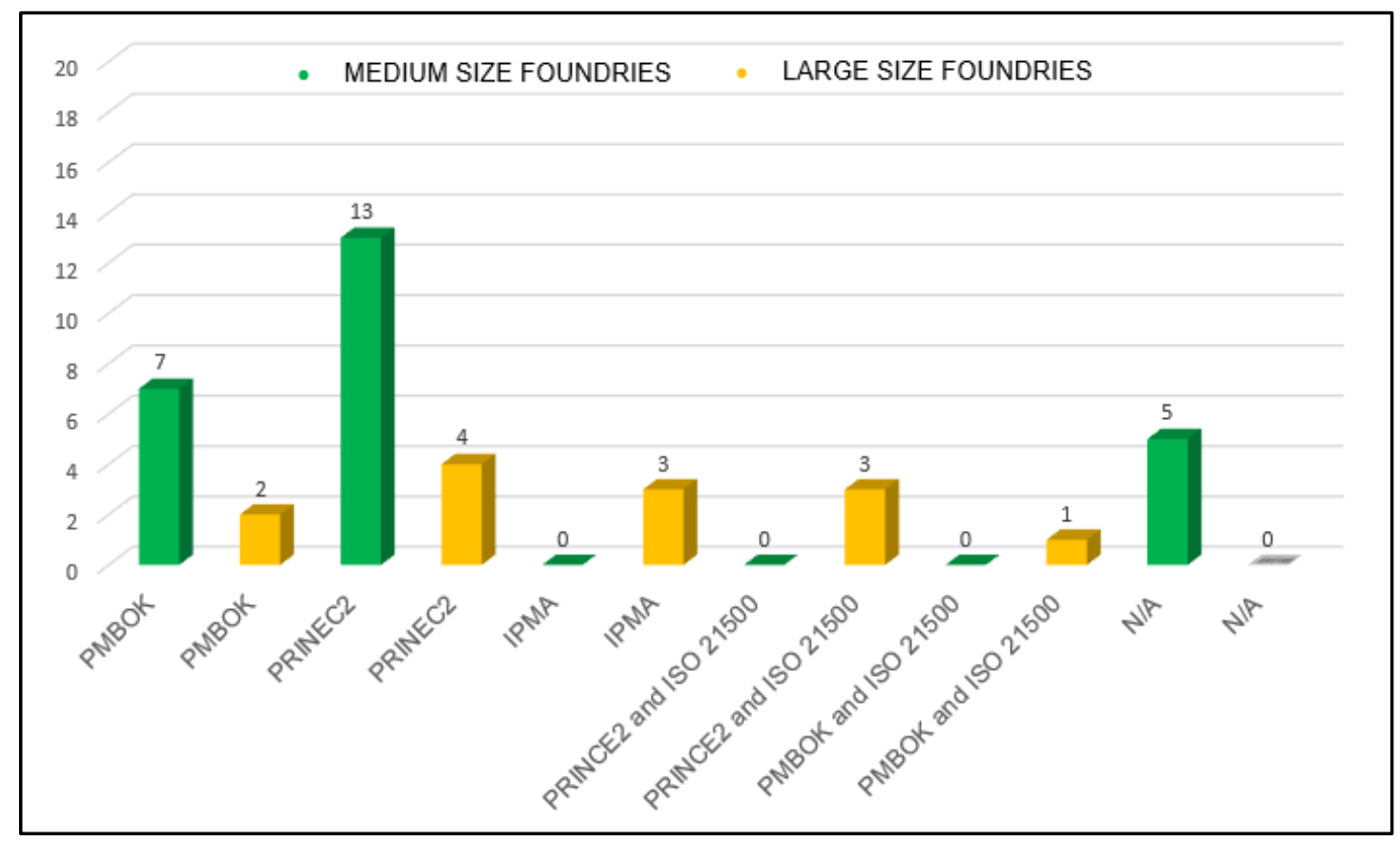

Figure 2 Medium size and large size foundries usage of project management methodologies

Figure 3 presents the outputs of how many project managers have a certification of project management (PMBOK, PRINCE2, IPMA, Other or N/A). Totally 149 project managers are working in our research sample (81 in middle size foundries and 68 in large size companies).

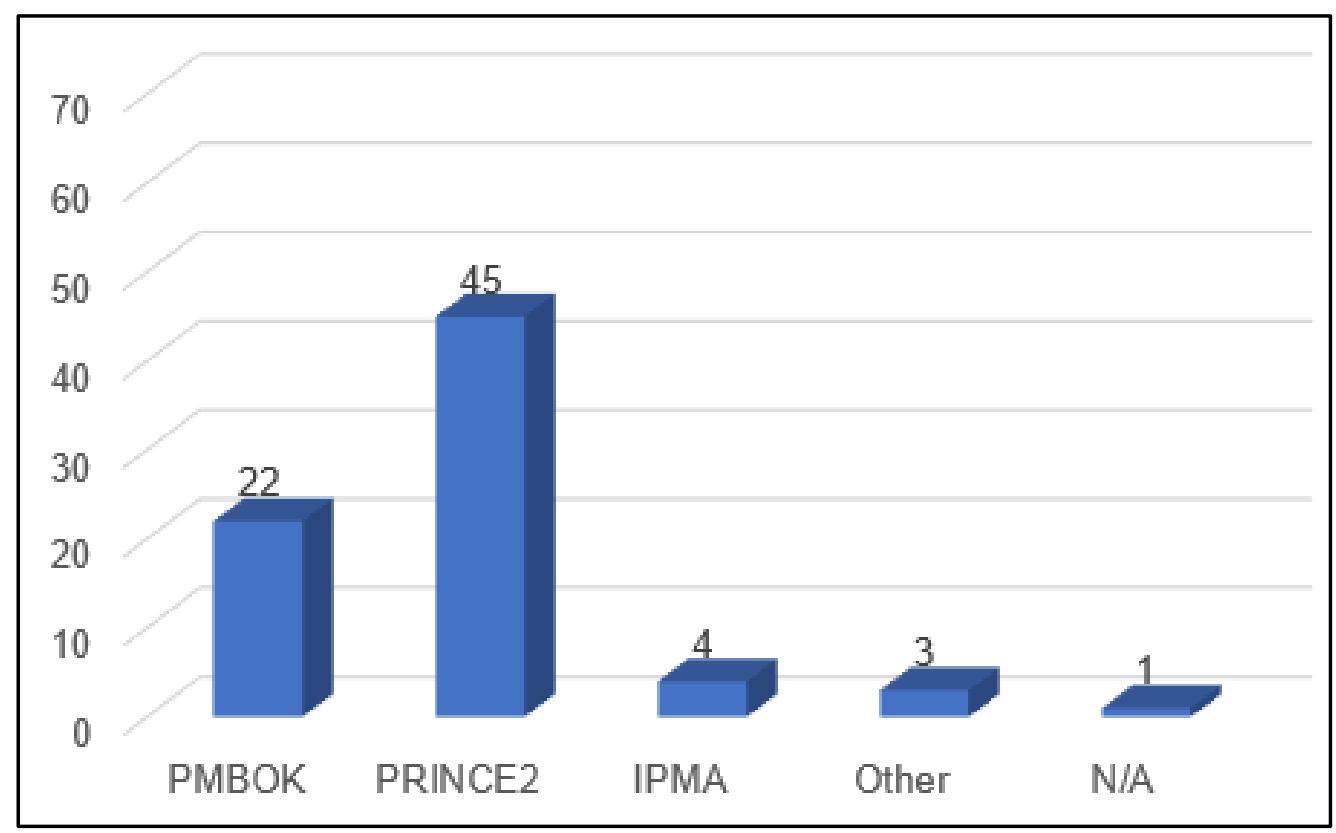

Figure 3 Project management certifications of project managers 
The results from Figure 3 presents that 65 (43.6\%) project managers don't have any project management certification. The most popular certification is PRINCE2 - $45(30.2 \%)$ and the second one is PMBOK - 22 $(14.7 \%)$. Only 4 project managers have IPMA certification (2.7\%). 13 project managers $(8.7 \%)$ have Other certification internal or external out of proposed options.

Figure 4 presents the comparison of project managers certification between medium size and large size foundries.

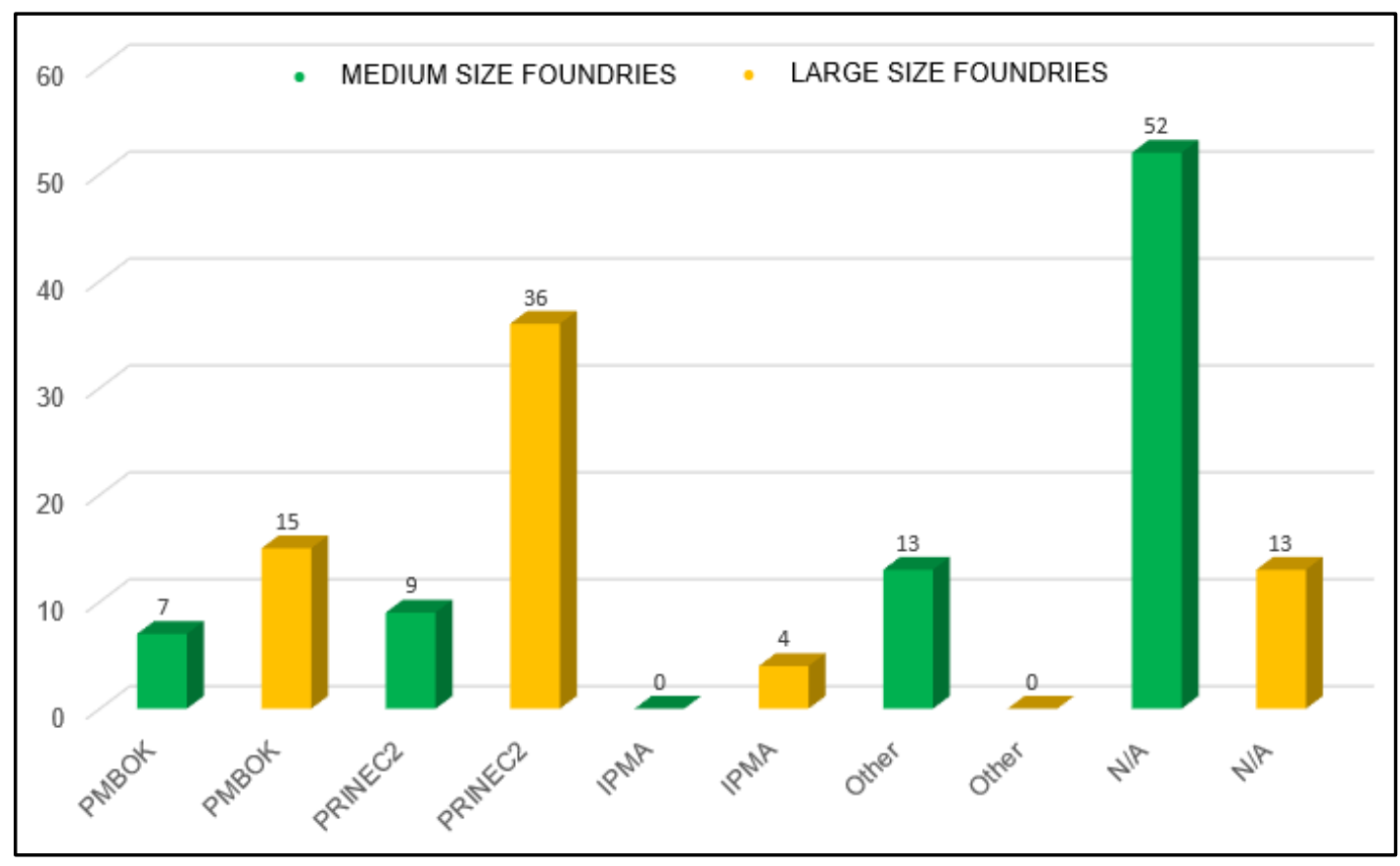

Figure 4 Medium size and large size foundries project manager certifications

Based on Figure 4 results, we can see that the most uncertified project managers could be find at medium size foundries - $52(34.8 \%)$. However, also in large size companies there are uncertified project managers $13(8.7 \%)$. The most popular certification is PRINCE 2 (medium size foundries -9 project managers $(6.0 \%)$ and in large size companies -36 project managers (24.2\%)). PMBOK is in the second position (medium size foundries -7 project managers ( $4.7 \%$ ) and in large size companies -15 project managers $(10.0 \%)$. There are also 4 project managers with IPMA certification (2.7\%) and small amount of project managers with another type of certification $-13(8.7 \%)$. It is usually internal company internal certification, external training or agile (scrum) certification.

\section{DISCUSSION AND CONCLUSION OF THE RESEARCH}

The goal of the paper and research to analyze current usage of project management methodologies and trend of project manager certifications in foundries in EMEA region was fulfilled. The research questions were answered:

1) Which project management methodologies are currently used in EMEA foundries?

The most popular project management methodology in EMEA foundries is PRINCE2 (44.7\%) and the second one is PMBOK (23.6\%). IPMA methodology is used at the same level as combination of PRINCE2 and ISO 10006 (7.9\%). Combination of PMBOK and ISO 10006 has only $2.6 \%$. There are also $13.1 \%$ of companies that do not use any project management methodology. 
2) How many project managers of EMEA foundries have project management certification?

Based on our research, we can say that from total amount of 149 project managers, totally $65(43.6 \%)$ are not certified. 84 project managers have a certification of project management. 45 project managers $(30.2 \%)$ have PRINCE2 that is the most popular one. PMBOK certification has 22 project managers (14.7\%). Only 4 project managers have IPMA certification $(2.7 \%)$ and 13 project managers $(8.7 \%)$ have Other certification. In this Other group, internal or external certifications out of proposed options (f. e. Agile/Scrum) are included.

3) What are differences in project management methodologies and project managers certification in medium size and large size foundries?

From the project management methodologies perspective, medium size foundries have implemented only PRINCE2 and PMBOK or do not have any project management methodology. On the other hand, large size foundries have the biggest portion also in PRINCE2 and PMBOK, but we can find also IPMA and combination of ISO 10006 with PRINCE2 or PMBOK.

Related to project managers certification, medium size foundries have 55 from 81 project managers without any certification and the rest of 26 project managers have PRINCE2 (9), PMBOK (7) or Other (13) so the biggest portion is in Other group that includes internal training or external certification. From 68 project managers of the large size foundries, we can see that the most useful is PRINCE2 (36), followed by PMBOK (15). In the large size companies, there are also IPMA certified project managers (4). Only 13 project managers are not certified.

The research provides overview of project management methodologies usage and project managers certification trend in EMEA foundries. The sample of our research is relatively small but reliable. Future research could be focused on deeper analysis of usage in specific countries or regions around the whole world.

\section{ACKNOWLEDGEMENTS}

\section{The work was supported by the specific university research of Ministry of Education, Youth and Sports of the Czech Republic at VSB - Technical University of Ostrava, project no. SP2021/71.}

\section{REFERENCES}

[1] JAMALI, G., OVEISI, M. A Study on Project Management Based on PMBOK and PRINCE2. Modern Applied Science. 2016, vol. 10, no. 6, pp. 142-146.

[2] RADUJKOVIC, M., SJEKAVICA, M. Project Management Success Factors. Creative Construction Conference. Primosten: Elsevier Ltd., 2017, pp. 607-615.

[3] MUSTARO, P., ROSSI, R. Project Management Principles Applied in Academic Research Projects. Issues in Informing Science and Information Technology. 2013, vol 10, pp. 325-340.

[4] PAWAR, R.P., MAHAJAN, K.N. Benefits and Issues in Managing Project by PRINCE2 Methodology. International Journal of Advanced Research in Computer Science and Software Engineering. 2017, vol. 7, no. 3, pp.190-195.

[5] BARTOŠKA, J., FLÉGL, M., JARKOVSKÁ, M. IPMA Standard Competence Scope in Project Management Education. International Education Studies. 2012, vol 5, no. 6, pp. 167-176.

[6] INGASON, H.T. Best Project Management Practices in the Implementation of an ISO 9001 Quality Management System. In: 28th IPMA World Congress. 2014, pp. 192-200.

[7] DASI, A., PEDERSEN, T., BARAKAT, L.L., ALVES, T.R. Teams and Project Performance: An Ability, Motivation, and Opportunity Approach. Project Management Journal. 2021, vol. 52, no. 1, pp. 75-89.

[8] MACEK, W. Methodologies of Project Management. Contemporary Economics. 2010, vol. 4, no. 4, pp. 267-280.

[9] TARI, J.J., MOLINA-AZORIN, J.F., HERAS, I. Benefits of the ISO 9001 and ISO 14001 standards: A literature review. Journal of Industrial Engineering and Management. 2012, vol 5, no. 2, pp. 297-322. 
[10] MATOS, S., LOPES, E. Prince2 or PMBOK - a question of choice. In: CENTERIS 2013 - Conference on Enterprise Information Systems. 2013, vol. 9, pp. 787 - 794.

[11] WALKER, D.H.T., WALKER-LLOYD, B. Rethinking project management: Its influence on papers published in the international journal of managing projects in business. International Journal of Managing Projects in Business. 2016, pp. 1-30.

[12] BUSHUYEV, S.D., WAGNER, R. IPMA Delta and IPMA Organisational Competence Baseline (OCB): New approaches in the field of project management maturity. International Journal of Managing Projects. 2014, vol. 7, no. 2, pp. 302-310.

[13] CHIN, C.M.M., SPOWAGE, A.C., YAP, E.H. Project Management Methodologies: A Comparative Analysis. Journal for the Advancement of Performance Information and Value. 2012, vol. 4, no. 1, pp. 106-118. 